\title{
Türkiye'deki Üniversite Kütüphanelerine Ait Web Sitelerinin İçerik Açısından Değerlendirilmesi
}

\author{
Content Evaluation of Turkish University Library Web Sites
}

\section{Umut $A I^{\star}$ ve Hatice Kübra Bahşişoğlu**}

\section{Öz}

Bu makalede, Türkiye'deki 37 üniversite kütüphanesinin Web sitelerinin içerikleri, seçilen 19 ölçüte dayalı olarak değerlendirilmiştir. Üniversite kütüphane Web sitelerinin çoğu, kütüphane ve sunulan hizmetlere ilişkin bilgi içermektedir. Kütüphanelerin yaklaşık \%60'ının çevrimiçi katalogları Web üzerinde bulunmaktadır. Üniversite kütüphane Web sitelerinin çoğunda yararı olabilecek bazı başka sitelere bağlantı olmasına karşın kendi sitesi içinde arama fonksiyonu olanların sayısı çok azdır. Üniversite kütüphanelerinin Web sitelerinin daha fazla bilgi, yararh dokümanlar ve hizmetler ile zenginleştirilmesi önerilmektedir.

Anahtar sözcükler: Web sitesi içeriği, Üniversite kütüphaneleri ve Web siteleri.

\section{Abstract}

This article examines the Web sites of Turkish university libraries. It analyzes the Web contents of 37 university libraries and evaluates them on the basis of 19 selected criteria. Most university librany Web sites contain information about the library and the services offered. Almost $60 \%$ of university libraries have their online catalogs on the Web. Although most university library Web sites contain links to some other useful sites, very few offer search capabilities within their own sites, suggesting that university library Web sites should be enriched with more information, useful documents and services.

Keywords: Web site content, University libraries and Web sites.

\footnotetext{
•Arş. Gör.; Hacettepe Üniversitesi Kütüphanecilik Bölürnü (umutal@hacettepe.edu.tr).

*Dr.; Hacettepe Üniversitesi Kütüphaneleri (kubra@hacettepe.edu.tr).
} 


\section{Giriș}

Bilgi toplumu olmayı hedefleyen ülkeler için Internet ve bilgi teknolojisi giderek önem kazanmaktadır. Günden güne daha fazla sayıda bilgisayar ağını ve kullanıcıyı birbirine bağlayan ve uluslararası bir ağ olan Internet, "dinamik, canlı ve büyük bir kütüphane, milyonlarca insanın katıldığı bir iletişim, dayanışma ve paylaşım ortamıdır" (Akgül, 1999, s. 1).

Elektronik postadan sonra en sık kullanılan Internet araçlarından birisi olan World Wide Web (WWW veya Web), 1989 yllında Cenevre'deki Avrupa Nükleer Araştırma Merkezi'nde (CERN) yerel alan ağı üzerindeki bilimsel bilginin dağıtılması ve yönetilmesi için Tim Berners-Lee'nin önderlik ettiği bir takım tarafından küçük çaplı bir proje olarak başlamıştır (Poulter, Tseng ve Sargent, 1999, s. 3). Web'in Internet'te kullanılmaya başlanması ise 1992 yıIına rastlamaktadır (Kredel, Meuer, Schumacher ve Strohmaier, 2000). Web standartları, Massachusetts Teknoloji Enstitüsündeki Bilgisayar Bilimleri Laboratuvarı önderliğinde kurulan bir endüstri topluluğu olan World Wide Web Konsorsiyumu (W3C) tarafından oluşturulmaya ve geliştirilmeye devam edilmektedir (Poulter ve diğerleri, 1999, s. 5).

Web, Internet'te dağıtılmış bilgiye serbest erişim ve esnek bir bilgi yayıncıIığ sunan bir hipermetin sistemidir (TERENA, 1999, s. 38). Bu sistem, herhangi bir belgedeki dosya, doküman ve benzeri elektronik nesneler arasındaki bağlantıların evrensel olarak izlenebilmesine olanak sağlayan pratik bir uygulamadır. Web, yüksek düzeyde esneklik ve kullanıcı kolaylığı sağlayan birçok ağ ve elektronik belge protokolü ile standart kullanmaktadır. Aktarım (transfer) protokolü, işaretleme (markup) dili, adresleme sistemi ve tarayıcı (browser) programlar bunlardan bazılarıdır (Tennant, Ober ve Lipow, 1996, s. 105).

- Hipermetin Aktarım Protokolü (HyperText Transfer Protocol $=$ HTTP): Uzak sunucular üzerinde depolanmış hipermetin belgelerin Internet arachlığıyla kopyasına erişmeyi ve görüntülemeyi destekleyen standart bir transfer protokolüdür (Tennant ve diğerleri, 1996, s. 105). 
- Hipermetin Işaretleme Dili (HyperTexł Markup Language = HTML): Web tasarımcılarının belgelerindeki çeşitli bağlantıları tanımlamalarına ve bunların hedeflediği yerleri belirlemelerine olanak veren bir işaretleme dilidir (Tennant ve diğerleri, 1996, s. 105).

- Tekbiçim Kaynak Buldurucu (Uniform Resource Locator = URL): Internet üzerinde bir bilgisayarda depolanmış herhangi bir objenin yerini tek biçimde tanımlayan ve bir kaynaktan diğerine bağłantıları belirleyen bir standarttır (Tennant ve diğerleri, 1996, s. 105).

- Tarayıcı (Browser): Protokoller ve standartlar yardımıyla kullanıçının erişim sürecini kontrol eden ve bağlantıları aktif hale getiren Netscape Navigator veya Internet Explorer gibi bif programdır (Rowley, 1998, s. 186).

Önceleri akademik ağlarda gelişen Internet ve Web, başta iş dünyasł olmak üzere her alanda yayılmakta, bilgi ve kütüphane hizmetlerine de uzaktan erişim olanağı sunmaktadır. Bu makalede, Türkiye'de üniversite kütüphanelerine ait Web sayłalarının içeriği, özellikle kütüphanelere yönelik ölçütlere uygunluğu açısından incelenmektedir.

\section{Kütüphane Web Sitelerinin Değerlendirilmesi}

Aynı sunucu üzerine konulan -genellikle birbiriyle ilgili- sayfaların koleksiyonu "Web sitesi", HTML formatında erişilebilecek bir dosya "Web sayfası", bir sayfa veya bağlantılı sayfalar "Web dokümanı" olarak anılmaktadır (Poulter ve diğerleri, 1999, s. 13).

Bir Web sitesinin oluşturulmasında ve yönetiminde amaç, kullanıcılara yararlı bir hizmet sağlamak ve kuruluşun hizmetlerini duyurmak için uygun bir pencere açmaktır. Bir Web sitesi projesine başlandığında, öncelikle sitenin içeriği ve düzenine karar verecek olan hedefler ve politikalar tanımlanmalıdır (Rowley, 1998, s. 193). Bir Web sitesinin niteliği, hazırlama ve yönetim süreci boyunca sorumlu kişilerin becerilerine, zamana, parasal kaynağa, yazılım ve donanıma bağlıdır. Bunlardan en önemlisi, sorumlu kişilerin becerileri olarak görülmektedir (Clyde, 2000, s. 98). Kimi durumlarda tasarım ve içerik 
Web tasarımcısı (Webmaster), Web sayfası komitesi veya bir Web takımı tarafından kontrol edilmektedir (Quinn, 1999, s. 305). Genellikle Web sitesinde nelerin yer alıp nelerin almayacağına ilişkin kararları alan kişi ya da kişilerle, Web sitesini meydana getiren kişi ya da kişiler farklı olmaktadır (White ve Raman, 1999, s. 408).

Web sitelerinin değerlendirilmesinde jki nokta ön plana çıkmaktadır: Tasarım ve içerik. Tasarım açısından değerlendirme yapılırken tipografi, grafik ve tablolar, çerçeveler, arka alan, boşluklar, kullanılan renkler ve sayfayı oluşturan diğer unsurlar dikkate alınmaktadır. Web sitelerinin içerik olarak değerlendirilmesinde ise, sitenin amacı, sunulan bilgi ve hizmetler ile bağlantılar önem taşımaktadır. December'a (1994, s. 13) göre bir Web sitesindeki bilginin kalitesini oluşturan etmenler doğruluk, erişilebilirlik, kullanılabilirlik, anlaşılabilirlik ve anlamlılık olarak sıralanmaktadır. Quinn'e (1999, s. 306) göre bir Web sayfasının içeriği sayfayı meydana getiren en önemli unsurdur. Çünkü tasarım ne derece başarılı olursa olsun, bir sayfanın içeriği zayı ise o sayfanın kullanımı sınırlıdır. Bununla birlikte, etkili bir Web sitesi meydana getirmek için iyi bir tasarım da gereklidir (Balas, 2000, s. 56).

Web siteleri ile ilgili olarak yapılan çalışmalar genelde Web tasarımı, özelde belli alanlara yönelik sitelere/sayfalara ilişkin yazılar ve araştırmalar halinde görülmeye başlanmıştır. İlk olarak Web sitesi/sayfası hazırlamaya yönelik çalışmalar, tasarım aşaması için öneriler, kurallar, örnekler, yazılar şeklinde literatürde yerini almıştır (Jurist, 1996; Nicotera, 1999). Daha sonra araştırmaya yönelik, Web sitelerinin tasarım ve içerik açısından değerlendirilmesi üzerinde yoğunlaşan makaleler (Agingu, 2000; Chisenga, 1998; Clausen, 1999b) yayımlanmıştır. McClements ve Becker (1996, s. 17) Web sayfası değerlendirme ölçütlerini içerik, tasarım ve teknik açılardan gruplandırmışlardır. Bazı çalışmalarda Web sayfalarının tasarımında nelerin yapılmaması gerektiğine ilişkin bilgiler verilmekte (Balas, 1999, s. 46-48; Clyde, 1999, s. 58-59), bazılarında ise başarılı Web sayfalarının nası olması gerektiğine ilişkin bilgi veren rehber kaynakların neler olduğu saptanmaya çalışılmakta ve var olan Web sayfalarının söz konusu rehber kaynaklara sadık kalıp kalmadığı ince- 
lenmektedir (D'Angelo ve Little, 1998, s. 71). Web sayfaları ile ilgili temel bilgiler, kurallar, öneriler, Web tasarımında kullanılan resim ve benzeri görüntülere ilişkin dosyalar ve bağlantılara sahip ücretli/ücretsiz Web siteleri giderek çoğalmaktadır. Jakob Nielsen'in hazırladığı ve sürekli güncelleştirilen sitede (http://www.useit.com) Web tasarımı ile ilgili sıklıkla yapılan yanlışlıklar ve benzeri bilgiler kısaca listelenmektedir.

Internet'in yaygınlaşması kütüphane hizmetlerinde yeni olanaklar yaratmakta, Web araçłarının gelişmesi de bilgiye yerel ve uluslararası boyutta erişimi kolaylaştırmaktadır. Günümüzde küçük-büyük pek çok işletme gibi kütüphaneler de Web sayfaları ile Internet’te yer almaktadır. Üniversite kütüphaneleri ise kullanıcılara sundukları hizmetleri tanıtmak, kütüphane hakkında güncel bilgi vermek, çevrimiçi ve CD-ROM veri tabanlarına, elektronik kaynaklara, kütüphanenin kataloğuna ve ürettiği veri tabanlarına uzaktan erişim sağlamak, kullanıcıların Internet'i keşfetmesine yardımcı olmak, toplumsal projeler için bilgi desteği sağlamak amacıyla Web siteleri oluşturmaktadır (Clyde, 2000, s. 97).

Web sitelerinin kütüphane ve bilgi hizmetleri alanında da yaygınlaşması ile içerik ve tasarım açısından yapılan çalışma, makale, Web sayfası ve elektronik tartışma listesi sayısı artmaktadır. Özellikle kütüphane Web siteleri (Chisenga, 1998), Web standartları (McClements ve Becker, 1996), kuralları, başarılı sitelerin özellikleri, kullanıcıların beklentileri (Cottrell ve Eisenberg, 1997), hizmetlerin Internet'te pazarlanması (Balas, 1998), değerlendirme ve belli bir tür ya da hizmete yönelik sayfaları inceleyen araştırmalar (Agingu, 2000; Quinn, 1999; Clausen, 1999a; 1999b) yaygınlaşmaktadır. Stover (1997, s. 55) kütüphane Web sitelerinin amaç ve işlevlerinin kütüphane türüne bağlı olduğunu ifade etmektedir.

Literatürde bir kütüphane Web sitesinde bulunması öngörülen temę özelliklèrin neler olduğuna ve bu özelliklerin değerlendiriimesine ilişkin çalışmalara da rastlanmaktadır (Agingu, 2000, s. 33; Chisenga, 1998, s. 50). Değişik kułlanıcı gruplarına hizmet veren ve farklı olanaklara sahip kütüphanelerin 
Web siteleri de birbirinden farklılıklar göstermektedir. Kütüphanelerin Web sitelerinde bulunması gereken temel bilgiler dört başlık altında toplanmaktadır (Agingu, 2000, s. 32; Chisenga, 1998, s. 51-52; Clausen, 1999a, s. 6; Cohen ve Still, 1999, s. 280; Rowley, 1998, s. 192):

- Temel kütüphane bilgileri: Çalışma saatleri, bağlanı kurulacak kişiler, adresler, duyurular, hizmetler ve politikalarla ilgili bilgiler ve bağlantılar.

- Kütüphane ve bilgi hizmetleri: Kataloğa uzaktan erişim. Web'de çevrimiçi katalog tarama arayüzü (interface) geliştirme, kütüphane tanıtımı, yeni enformasyon hizmetleri, tam metin ve bibliyografik veri tabanları ile diğer Internet kaynaklarına bağlantılar.

- Etkileşimli Web sayłaları: Geribildirim (feedback) ve çeşiti hizmetlere uygun olarak doldurulabilecek standart formlar, sipariş istekleri, kütüphane kaynakları ve kütüphane politikası hakkında görüşler, kütüphanelerarası ödünç verme ve belge sağlama için formlar, danışma soruları.

- Uzaktaki bilgi kaynaklarına bağlantı; Kullanıcı kitlesine uygun seçilmiş ınternet kaynaklarına bağlantılar.

Bunların dışında, bağlı olunan kuruluşun ana sayfası ile kütüphane ana sayfası arasında bağlantı olması, Web tasarımcısının adı ve adresì ile her sayfanın son güncelleme tarihine yer verilmesinin gerekliliği vurgulanmaktadır. Calışmamızda yukarıdaki gruplamaya dayanarak oluşturulan 19 ölçüte göre üniversite kütüphanelerinin Web siteleri değerlendirilmiştir.

\section{Yöntem}

Bu makalede, Türkiye'deki akademik kütüphanelerin Internet üzerinde kendilerini ve hizmetlerini nasıl sundukları araştırılmaktadır. Bu amaçla 37 üniversite kütüphane Web sitesi (bkz. Ek 1. Üniversite Kütüphanelerinin Web Sitelerinin Adresleri) 19-23 Ekim 2000 tarihleri arasında ziyaret edilmiştir.

Önceki çalışmalardan yararlanılarak oluşturulan 19 değerlendirme ölçütü (Bkz. Ek 2. Üniversite Kütüphanelerinin Web Sitelerini İ̧̧erik Açısından Değerlendirme Ölçütleri) doğrultusunda üniversite kütüphanelerinin Web sitele- 
ri değerlendirilmiştir. Bu ölçütlerin belirlenmesinde literatủrdeki özellikle içerik analizine yönelik çalışmalar esas alınmıştır. Belirlenen 19 ölçüt beş grup altında toplanmıştır. İlk grupta yer alan dört değerlendirme ölçütü Web sitesiyle ilgilidir (üniversitenin ana sayfasından kütüphanenin Web sitesine, kütüphanenin Web sitesinden üniversitenin ana sayfasına bağlantılar, kütüphane ana sayfasının son güncelleme tarihi ve yazarı). İkinci grupta yer alan beş ölçüt temel kütüphane bilgileriyle (adres, telefon numarası, çalışma saatleri, kullanım ve ödünç verme kuralları, vb. gibi) iilgilidir. Üçüncü grupta kütüphane tarafından sunulan hizmetlerle ilgili beş ölçüt saptanmıştır (çevrimiçi katalog ve süreli yayınlar listesine Web aracılı̆̆ıla erişilebilmesi, yeni yayınların duyurulması ve kütüphanenin abone olduğu veri tabanlarına ve elektronik süreli yayınlara bağlantı sağlanması). Dördüncü grupta yer alan dört ölçüt kütüphane Web sitesindeki etkileşimli sayfalarla ilgilidir (belge sağlama hizmetleri, arama, sıkça sorulan sorular sayfası ve geribildirim olanakları). Son ölçüt ise kütüphane Web sitesinde üniversite dışındaki başka sitelere bağlantı bulunup bulunmadığıyla ilgilidir.

Değerlendirmeyi kolaylaştırmak amacıyla belirlenen ölçütlerin eşit ağırlıkta olduğu varsayılmıştır. Ancak, kütüphane Web sitesindeki bilgilerin son güncelleme tarihinin kaydedilmiş olmasıyla kütüphanenin abone olduğu elektronik dergilere Web aracılığıyla erişim sağlanması kuşkusuz eşit ağırlıkII değildir.

Ziyaret edilen her üniversite kütüphanesinin Web sitesi belirlenen 19 ölçüte göre tek tek değerlendirilmiştir. Bu ziyaretler sırasında çalışmayan bağlantılar da tespit edilmiştir. Değerlendirme sonuçları Ek 3 'te (Üniversite Kütüphane Sitelerini İçerik Açısından Değerlendirme Tablosu) topluca verilmektedir. İnceleme sürecinde eriş̧ilemeyen veya bulunamayan sitelere ilişkin bağlantılar daha sonra tekrar denenmiş ve yeni bulgular eklenmiştir. Elde edilen veriler sayı ve yüzde olarak verilmiş ve yorumlanmıştır. 


\section{Bulgular}

Türkiye'de 53'ü devlet, 18'i vakıf olmak üzere toplam 71 üniversite bulunmaktadır (Yükseköğretim Kurulu, 2000). Devlet üniversitelerinin \%96'sının, vakıf üniversitelerinin ise \%83'ünün Web siteleri olduğu görülmektedir. Bu çalışmada devlet üniversitelerinin Web siteleri incelenmiştir. Araştırma sırasında, birkaç kez kontrol edilmesine rağmen, Niğde Üniversitesine ait URL bağlantısının çalışmadığı, Çanakkale Onsekiz Mart Üniversitesine ait sayłanın ise boş olduğu görülmüştür. Dolayısı ile bu iki üniversitenin ve kütüphanelerinin Web siteleri değerlendirilmemiştir. Incelenen toplam 51 üniversite sitesinin 37 'sinde (\%73) kütüphaneye ait bir Web sitesinin varlığı saptanmıştır.

\section{Kütüphanenin Web Sitesiyle ligili Değerlendirme}

Üniversite kütüphanelerinin Web sitelerini inceleme çalışması, üniversite ve kütüphane ana sayfaları arasındaki bağlantılar, kütüphane sitesinin tasarımcısının adı ve elektronik posta (e-posta) adresi ile sayfaların son güncelleme tarihlerinin olup olmadığının belirlenmesiyle başlamıştır.

Üniversite ana sayfalarındaki kütüphane siteleri farklı yerlerde bulunabilmekte, bu sitelerin bağlantıları bazen ana sayfada kolaylıkla görülürken, bazen de alt sayfaların içinde aranması gerekmektedir (King, 1998, s. 463). KulIanıcılar, genellikle kütüphane sayfasının adresini ezberlemek yerine üniversite ana sayfasından bulmayı tercih etmektedirler (Shemberg, 2000, s. 180181). İncelenen 51 üniversite Web sitesinin 35 'inde (\%67) kütüphane ana sayfasına veya Web sitesine bağlantı mevcuttur. Bu durum, özellikle sanal ortamda hizmetlerin yaygınlaşması ve işbirliği çalışmalarının artışı göz önüne alındığında uzaktaki kullanıcılar için üniversite kütüphanesine kolaylıkla erişime olanak vermesi açısından önemlidir. Kütüphaneye bağlantısı olmayan veya bağlantı kurulmuş olmasına rağmen çeşitli nedenlerle çalışmayan iki (\%4) üniversite ana sayfası vardır. Kütüphane sitesinden üst kuruluş ana sayfasına bağlantının olması ise özellikle kendi kullanıcılarının üniversite ana 
sayfasına kolayca dönüşünü sağlamaktadır. Ziyaret edilen kütüphane sitelerinin 22'sinde (\%59) üniversite ana sayfasına dönüş olanağı bulunmaktadır.

Kütüphane sayfalarının ne zaman hazırlandığı veya değiştirildiği özellikle içerdiği bilginin güncelliğini belirlemede önemlidir. Ziyaret edilen 37 siteden sadece altısında (\%16) son güncelleme tarihine ilişkin bilgi bulunmaktadır. Bunlar Adnan Menderes, Hacettepe, ITÜ, ODTÜ, Sakarya ve Selçuk Üniversitelerinin kütüphaneleridir.

Web tasarımı açısından dikkat edilen ölçütlerden birisi de sitede/sayfalarda Web tasarımcısına ait isim, e-posta adresi gibi erişim bilgilerinin bulunmasıdır. Böylece kütüphaneye ait siteyi/sayfaları kimin hazırladığı belirlenebilmektedir. Diğer bir yararı da Web sayfası hakkındaki görüşlerin doğrudan Web tasarımcısına iletilebilmesidir. İncelenen sitelerin 15 'inde (\%41) tasarımcının adı ve/veya e-posta adresi bulunmaktadır.

Temel Kütüphane Bilgileri lle ilgili Değerlendirme

Web sitesinde özellikle uzaktaki kullanıcılara, kütüphanenin amacını, erişim bilgilerini, çalışma saatlerini, personeli, verilen hizmetleri anlatan doğru ve güncel bilgilerin olması önem taşımaktadır. Araştırmada bir kütüphane Web sitesinde yer alması beklenen temel kütüphane bilgilerinin olup olmadığı kontrol edilerek elde edilen veriler Tablo 1'de gösterilmektedir.

Tablo 1. Kütüphane Web sitelerindeki temel kütüphane bilgileri ( $N=37$ )

\begin{tabular}{|c|c|c|c|c|c|c|}
\hline \multirow[b]{2}{*}{ Kütüphane Web sayfasında yer alan bilgiler } & \multicolumn{2}{|c|}{ Var } & \multicolumn{2}{|c|}{ Yok } & \multicolumn{2}{|c|}{$\begin{array}{c}\text { Bağlantı var, } \\
\text { ama çalışmıyor }\end{array}$} \\
\hline & $N$ & $\%$ & $N$ & $\%$ & $N$ & $\%$ \\
\hline Kütüphane hakkında bilgi & 29 & 78 & 7 & 19 & $t$ & 3 \\
\hline Kütüphane erişim bilgileri & 19 & 51 & 18 & 49 & - & - \\
\hline Çalışma saatleri & 23 & 62 & 14 & 38 & - & - \\
\hline Personel hakkında bilgi & 27 & 73 & 9 & 24 & 1 & 3 \\
\hline Kullanım ve hizmetler hakkında bilgi & 24 & 65 & 12 & 32 & 1 & 3 \\
\hline
\end{tabular}


Kütüphanenin genel olarak tanıtımını, amacını, tarihçesini, yönetmeilğini veren kütüphane Web sitelerinin sayısı 29'dur (\%78). Bunun dışında bir (\%3) kütüphanenin sayfasında bağlantının kurulduğu ancak çalışmadığı görülmektedir.

Temel kütüphane bilgileri arasındaki erişim bilgilerinin (adres, telefon, faks) \%51 (19 kütüphane) oranında kaldığı görülmektedir. Kullanıcıların söz konusu bilgileri ilk olarak kütüphane Web sayfasında arayacağı düşünüldüğünde, diğer kütüphanelerin de sayfalarına bu bilgileri eklemeleri yararlı olacaktır.

Temel kütüphane bilgileri açısından önemli bir ölçüt de Web sitesinde kütüphanenin çalışma saatlerinin bulunmasıdır. Sayfalarında çalışma saatlerini veren 23 kütüphane (\%62) vardır.

Kütüphane yöneticileri ve kütüphanecilerin kimlikleri, telefon ve/veya e-posta adresleri gibi bilgileri Web sayfalarından sunan $27(\% 73)$ kütüphane saptanmıştır.

Kütüphane kullanıcılarına, genel kullanım, kütüphane içinde dikkat edilmesi gereken kurallar, ödünç verme gibi hizmetlerle ilgili bilgileri veren sayfalara sahip olanların sayısı 24'tür (\%65). II gili sayfa için kurulan bağlantısı çalışmayan bir (\%3), bu bilgileri içermeyen 12 (\%32) kütüphane Web sitesi bulunmaktadır.

Yukarıdaki sayılardan da anlaşıldığı gibi, üniversite kütüphanelerinde genelde basılı bir broşürün kopyası niteliğinde olan ve kütüphane hakkında temel bilgileri içeren sayfaların hazırlandığı ve giderek geliştirildiği söylenebilir.

\section{Kütüphanenin Verdiği Bilgi Hizmetlerivle ilgili Değerlendirme}

Bir kütüphane sitesinde, Internet ortamında verilen çeşitli bilgi hizmetleri de sunulmaktadır. Kütüphane tarafından hazırlanan çeşitli listeler, kataloglar, veri tabanları ve duyurular gibi daha önce geleneksel araçlarla verilmeye çaIışılan bilgi ve hizmetler, günümüzde Internet ortamına taşınmaktadır. Ziyaret edilen kütüphane sayfaları bu açıdan da değerlendirilmiştir. 
Bir kütüphanenin en önemli hizmetlerinden birisi, sahip olduğu koleksiyonu kullanıcılarına tanıtmasıdır. Bu, iyi bir katalog ile gerçekleşebilir. Çevrimiçi katalogların geliştirilen arayüzlerle Web üzerinden taranabilir olması, bir kütüphane için olmazsa olmaz ölçütlerden birisi haline gelmektedir. Kütüphane otomasyonu konusunda yeni sayılabilecek bir geçmişe sahip olduğumuz düşünülürse, incelenen 37 sitenin 22'sinde (\%59) çevrimiçi kataloğun bulunması umut verici bir durumdur (Tablo 2). Ayrıca dört (\%11) kủtüphane kataloğunun incelenen tarihlerde çalışmamasına veya aktif hale getirilmemiş olmasına rağmen bağlantılarının yapılması yakında bu kütüphanelerìn kataloglarına da Internet'ten erişilebileceğine işaret etmektedir. Halen çevrimiçi kataloğu bulunmayan 11 (\%30) kütüphanenin ise genellikle son dönemde kurulmuş üniversitelere ait olduğu anlaşılmaktadır.

Tablo 2. Kütüphane Web sitelerindeki bilgi hizmetleri hakkında bilgiler ( $N=37)$

\begin{tabular}{|c|c|c|c|c|c|c|}
\hline \multirow[b]{2}{*}{ Kütüphane Web sayfasinda yer alan bilgiler } & \multicolumn{2}{|c|}{ Var } & \multicolumn{2}{|c|}{ Yok } & \multicolumn{2}{|c|}{$\begin{array}{c}\text { Bağlantı var, } \\
\text { ama çalışmyyor }\end{array}$} \\
\hline & $N$ & $\%$ & $\bar{N}$ & $\%$ & $N$ & $\%$ \\
\hline Cevrimiçi katalog & 22 & 59 & 11 & 30 & 4 & 11 \\
\hline Süreli yayın listesi & 28 & 76 & 9 & 24 & - & 0 \\
\hline Süreli yayın mevcutlar listesi & 16 & 43 & 19 & 51 & 2 & 5 \\
\hline Yeni yayınlar / duyurular & 24 & 65 & 11 & 30 & 2 & 5 \\
\hline E-dergi/e-veri tabanları & 29 & 78 & 8 & 22 & - & 0 \\
\hline
\end{tabular}

Kütüphane koleksiyonu içinde önemli bir yere sahip olan süreli yayınların listesi ve mevcutlar bilgisi, kullanıcıların bu kaynaklardan daha etkin biçimde yararlanması açısından değer taşımaktadır. Bu listeler, özellikle kütüphaneler arasında işbirliği ile belge sağlama hizmetini destekleyen temel hizmetlerden birisidir. Her dört kütüphaneden üçünün (28 kütüphane) sitesinde süreli yayınlarının listesi bulunmakta, bunlardan \%57'sinde (16 kütüphane) aynı zamanda süreli yayınların mevcutları da gösterilmektedir. Süreli yayın koleksiyonunu mevcutları ile birlikte çevrimiçi katalogları içinde taranabilir durumda veren kütüphanelerin sayısı artmaktadır. 
Kütüphanenin sağladığı yeni kaynaklar ve hizmetlerin kullanıcılara en kısa zamanda duyurulması için yeni yayınlar velveya duyuru sayfalarının hazırlanması tercih edilmektedir. İncelenen kütüphanelerden $24{ }^{\prime} u ̈(\% 65)$ sitelerinde bu amaçla yeni yayıntar ve/veya duyurular saytasına yer vermektedir. İki kütüphane sitesinde bu sayfaların hazırlanmakta olduğu anlaşılmaktadır.

Son yıllarda Internet üzerindeki çevrimiçi veri tabanlarının sayısı giderek artmaktadır. Bazı üniversite kütüphaneleri birleşerek bir konsorsiyum (Anadolu Üniversite Kütüphaneleri Konsorsiyumu-ANKOS) ${ }^{1}$ kurmuşlar ve konsorsiyuma üye kütüphaneler çeşitli veri tabanlarına erişim sağlamışlardır. Çoğu üniversite kütüphaneleri 2000 yılı başında Ulusal Akademik Ağ ve Bilgi Merkezi (ULAKBIM) tarafından başlatılan Veri Tabanları ve Elektronik Dergiler Ev Sahipliği (VEDES) ${ }^{2}$ projesi aracılığıyla Institute for Scientific Information (ISI) ve SilverPlatter veri tabanlarına erişme olanağı bulmuşlardır. Gerek konsorsiyumun bir üyesi olarak gerekse tek başına çevrimiçi veri tabanlarına abone olan 29 (\%78) kütüphane mevcuttur. Internet aracılığı ile sunulan bu hizmet kapsamında, bibliyografik bilgi ve tam metin veren elektronik dergi veri tabanları bulunmaktadır. Konsorsiyum aracıliğı ile abone olunan veya deneme kullanımı sağlanan veri tabanlarına ilişkin bağlantılar çoğunlukla kütüphane sitesinde yer almakta, bazılarında ise sadece bağl'ı olduğu üniversitenin sayfaları içinde görülmektedir.

Kütüphane Web Sitelerindeki Etkileşimli Sayfalarla ligili Değerlendime

Kullanıcıların kütüphaneye gelmeden de bilgi hizmetłerinden yararlanmasını sağlayan etkileşimli Web sayfaları hazırlanmaktadır. Kütüphane sitelerimizde çeşitlli formlar, arama motorları, yardım ve sıkça sorulan sorular (SSS) sayfalarının sayısının, Tablo 3’te de görüldüğü gibi, yeterli olmadığı dikkati çekmektedir.

\footnotetext{
ANKOS-Anadolu Üniversite Kütüphaneleri Konsorsiyumu hakkında ayrıntilı bilgi için bkz. . http:/hww lib.metu.edu.tr/ankosi

${ }^{z}$ VEDES-Veri Tabanları ve Elektronik Dergiler Ev Sahpliği projesi hakkında ayrıntıiı bilgi için bkz : http:/Www.ulakbim.gov.tr/proje/er/vedes/
} 
Tablo 3. Kütüphane Web sitelerindeki etkileşimli sayłalar ( $N=37$ )

Bağlantı var,

\begin{tabular}{|c|c|c|c|c|c|c|}
\hline \multirow[b]{2}{*}{ Kütüphane Web sayfasinda yer alan bilgiler } & \multicolumn{2}{|c|}{ Var } & \multicolumn{2}{|c|}{ rok } & \multicolumn{2}{|c|}{ ama çalışmyyor } \\
\hline & $N$ & $\%$ & $N$ & $\%$ & N & $\%$ \\
\hline Belge sağlama hizmetine destek & 21 & 57 & 15 & 40 & 1 & 3 \\
\hline Site içinde arama yeteneği & 3 & 8 & 34 & 92 & . & 0 \\
\hline Yardım veya SSS sayfası & 2 & 5 & 34 & 92 & 1 & 3 \\
\hline Geribildirim olanağı & 27 & 73 & 10 & 27 & - & 0 \\
\hline
\end{tabular}

Son yıllarda özellikle üniversite kütüphaneleri arasında, belge sağlama hizmetlerinde işbirliği çabalarında bir arıı̧ göze çarpmaktadır. YÖK Dokümantasyon Merkezi ile başlayan belge sağlama hizmeti, ULAKBiM'in işbirliği ile Internet'in hızı iletişim olanakları da kullanılarak geliştirilmektedir. Sitesinde belge sağlama hizmetlerine e-posta veya elektronik form (e-form) biçiminde destek veren 21 (\%57) kütüphane gerek kendi olanaklarıyla gerekse ULAKBIM üzerinden bu hizmeti vermeye çalışmaktadır. Bunun yanı sıra inceleme süresince bir kütüphanenin bu hizmete ilişkin bağlantısının cevap vermediği anlaşı|mışıtır.

Çok sayıda sayfa ve bağlantı içeren büyük Web siteleri içinde aranılan sayfayı veya bilgiyi bulmak giderek zorlaşmaktadır. Bu amaçla site içinde arama yapabilen tarama motorlarının kullanımının artığı gözlenmektedir. Ancak incelenen kütüphane sitelerinin sadece üçünde (Adnan Menderes, Boğaziçi, İnönü Üniversitesi Kütüphaneleri) site içinde arama motoru vardir. Bu sayının az olması, sitelerin kendi içinde tarama gerektirecek derecede büyük olmaması veya Web tasarımclarının bu türde Web hizmetlerine gereken önemi vermemesi gibi nedenlere dayanmaktadır.

Internet üzerinde kütüphane hizmetlerine dayalı yardım ve/veya SSS sayfaları kullanıcılara bilgi vermek açısından yararlı olmaktadır. Bu amaçla iki kütüphane (ODTÜ, Boğaziçi Üniversitesi), Internet'e yönelik hizmetlerine dayalı yardım veya SSS sayfaları hazırlamışlardır. Ege Üniversitesi Kütüphanesinin sitesinde benzer bir bağlantı görülmekte ancak erişim sağlanamamak- 
tadır. Bu sayının azlığı ise, ya böyle sayfaları hazırlamanın zaman alıcı ve sona bırakılan işłerden biri olması ya da Web sitesini oluşturanlar tarafından gereksinim duyulmaması gibi nedenlerden kaynaklanabilir.

Kütüphanenin genel anlamda hizmetleri, özel istekler ve görüşlerin yönetime iletilebilmesi, kısaca geribildirimin alınabilmesi, kütüphanenin gelişimine önemli katkılar yapabilmektedir. Internet yaygınlaşmadan önce kişisel görüşme, telefon, posta gibi geleneksel iletişim kanalları ile yapılan geribildirim, günümüzde e-posta aracıı̆̆ıyla hızlı ve etkili biçimde gerçekleşebilmektedir. İncelenen sitelerden 27 'sinde e-form ve/veya e-posta adresine bağlantı biçiminde geribiidirim olanağı vardır. Kütüphanelerin yaygın biçimde Internet'ten gelen görüş ve önerilere açık olduğu, e-posta ile iletilen danışma sorularına yine e-posta yoluyla cevap verebildiği anlaşılmaktadır.

\section{Diğer Ilgili Sitelere Bağlantilar}

Kütüphaneler kullanıcı gereksinimlerini karşılamak amacıyla bilgi kaynağı niteliğindeki başka sitelere de bağlantı sağlayabilmektedir. Incelenen sitelerde kütủphane bilgileri ve hizmetleri dışında başka sitelere bağlantı sağlayan 29 (\%78) kütüphane bulunmaktadır. Genellikle diğer üniversite ve araştırma kütüphaneleri, Internet üzerinde serbest kullanımı olan danışma hizmetine destek olabilecek nitelikte kaynaklar, sanal kütüphaneler, tarama motorları, yayıncılar, kitabevleri, gazeteler vb. gibi bilgi verici sitelere bağlantılar yapılmaktadir.

\section{Yorum}

Saptanan ölçütler doğrultusunda genel bir değerlendirme yapıldığında, araştırma tarihi itibariyle Boğaziçi Üniversitesi Kütüphanesinin Web sitesi 19 öl-

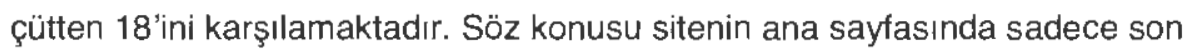
güncelleme tarihi bulunmamaktadır. Alt sayfalarda telif hakkı tarihi verilmek- 
tedir. Kütüphanenin ana sayfası kısa ve basit olarak tasarlanmış, kütüphane bilgileri ve hizmetlerine ait bağlantılar kolaylıkla görülecek biçimde listelenmiş ve bu bilgiler sayfa altında da tekrarlanmıştır.

Araştırma ölçütlerinden 15-18'ine sahip 10 kütüphane sitesinde, temel kütüphane bilgileri ve bilgi hizmetlerinin tamamına yakınının olduğu görülmektedir. Bu grupta Hacettepe, ITÜ, ODTÜ gibi köklü üniversite kütüphanelerinin yanı sıra yeni kurulan Sakarya, Adnan Menderes ve Kahramanmaraş Sütçü İmam üniversitelerinin kütüphanelerinin de yer alması sevindiricidir. Bu kütüphanelerin Web sitelerinde kolaylıkla tamamlanabilecek bir-iki ölçütün eksikliği yanında genellikle yardım veya SSS sayfaları ile site içinde arama fonksiyonu bulunmamaktadır.

İncelenen kütüphanelerden 15’i 10 ile 14 ölçütü sağlamaktadırlar. Söz konusu ölçütler genellikle kütüphane hakkında sayfalar ve bilgi hizmetlerine yöneliktir. Eksik birkaç sayfa/hizmet dışında bu kütüphanelerin sitelerinde çoğunlukla yardım veya SSS sayfaları ve site içinde arama fonksiyonuna rastlanmamaktadır. Bu grupta yer alan üniversiteler arasında 19 Mayıs, Cumhuriyet, Anadolu Üniversiteleri gibi nispeten daha eski ve köklü üniversitelerin kütüphaneleri de bulunmaktadır.

Diğer üniversite kütüphanelerinin siteleri (12 site) iki ile dokuz arasında değişen ölçütü karşılamaktadır. Bu sitelerden Kırıkkale, Mersin ve Uludağ Üniversitelerinin sayfalarında kütüphaneye bağlantı yapılmasına rağmen kütüphaneye ilişkin temel bilgilerin bile yer almadığı, bilgi hizmetlerine Web üzerinden erişilemediği saptanmıştır.

Sonuç olarak, üniversite kütüphanelerimizin hizmetlerini yavaş yavaş Web ortamına taşıdıkları gözlenmektedir. Ancak mevcut Web sitelerinin içerik açısından zenginleştirilmesi ve Web arac/lığıyla daha fazla hizmet sunulması gerekmektedir. 


\section{Sonuç ve Öneriler}

Dünyada olduğu gibi Türkiye'de de Internet'teki Web sitelerinin sayısı hızla artmaktadır. Kütüphaneler için Web siteleri, bir tanıtım aracı, hizmetlerini zamandan ve mekândan bağımsız olarak daha geniş kullanıcı kitlesine ulaştırma ortamı haline gelmektedir. Türkiye'deki üniversite kütüphaneleri ise bu gelişimin öncülüğünü yapmaktadır. Özellikle sitelerini geliştirmek veya yeni düzenlemek durumunda olan kütüphanelerde, kütüphanecilerin temel kütüphane bilgileri ve hizmetleri ile ilgili sayfaları hazıllamaları ve bilgi işlem birimleri ile işbirliğine giderek bunları sitelerine aktarmaları gerekmektedir.

Bư çalışmada 37 devlet üniversitesi kütüphanesine ait Web sitesi içerik açısından değerlendirilmiş, değerlendirme sonucunda birçok Web sitesinde kütüphaneyi tanıtıcı bilgilerin yer aldığı, bunun yanı sıra çevrimiçi katalog ve süreli yayın bilgilerinin de yavaş yavaş Web ortamına aktarıldığı görülmüştür. Ancak bazı üniversite kütüphanelerinin Web sayfalarında kütüphaneyle ilgili temel bilgiler dahi bulunmamaktadır. Web sitelerinin içerik ve hizmetler açısından zenginleştirilmesi ve arama, yardım vb. gibi özelliklerin Web sitelerine bir an önce eklenmesi gerekmektedir.

Günümüzde iyi bir kütüphane Web sitesinin doyurucu bir içeriğe ve etkili bir tasarıma sahip olması beklenmektedir. Bu doğrultuda özellikle üniversite kütüphanelerinin Web sitelerinin tasarımı ve geliştirilmesinde dikkat edilmesi gereken noktalar şöyle özetlenebilir:

- Bir kütüphane Web sitesi, kütüphanenin amacına, hedeflerine ve görevlerine uygun biçimde hazırlanmalı, kullanıcı gruplarının bilgi arama davranışı ve bilgi gereksinimleri dikkate alınmalıdır.

- Kütüphane yönetimi Web sitesi oluşturmak ve yönetmek için kaynak sağlamalıdır. Kaynak olarak donanım, yazılım, personel ve zamana gereksinim vardır.

- Web sitesinin hazırlanması ve yönetiminin sorumluluğu bir Web tasarımcısına veya bir Web grubuna verilebilir. Web saytaları hakkındaki son karar, Web sorumlularına bırakılabileceği gibi kütüphane yönetimine de ait olabilir. Ayrıca Web sorumlusu/grubu, yeni eğilimlerin tartışı- 
dığı toplantılara ve sürekli eğitim etkinliklerine katılmak için maddi açıdan desteklenmelidir.

- Web sayfaları mümkün olduğunca kısa, basił ve kullanışlı (user-friendly) olmalı, önemli bilgiler sayfaların üșt kısmında verilmelidir. Site düzeninin karışık ve düzensiz olmașı, kuilanıcı için karmașa ve kaybolma duygusu yaratabileceğinden Web içeriği belirli bir mantıksal düzende oluşturulmalıdır.

- Web'deki bilgiler ve bağlantılar doğru ve güncel olmalı, güncelliğini yitiren veya çalışmayan bağlantılar kaldırılmalıdır. Uzun dokümanlar ve birbiriyle ilgili sayfalar arasında dolaşmayı kolaylaştıran simgeler ve bağlantılar kullanılmalıdır.

- Metin açık ve anlaşılır olmalı, dilbilgisi ve yazım kurallarına uygun biçimde yazılmalıdır.

- Kullanıcılar için Web üzerinde Internet kaynakłarına erişim kolaylıkları, bibliyografik tanımlar, kılavuzlar, rehberler, sıkça sorulan sorular, yardım sayfaları hazırlanmalıdır. Web'de yer alan bilgi kaynaklarına ilişkin entellektüel haklar konusunda kullanıcılar bilgilendirilmelidir.

- Kütüphane ile bağlı olduğu üniversitenin ana sayfaları arasında kullanıcı tarafından kolaylıkla görülebilen bağlantılar bulunmalıdır.

- Web sitesinin içeriği, özellikle akademik yıl başlarında gözden geçirilmeli, yeni kaynaklar ve hizmetler eklenmelidir. Yapılan değişiklikler düzenli olarak kullanıcı grubuna duyurulmalıdır.

- Internet'te verilen hizmetler/sayfalar için özel yazılımlardan kaçırı/malı, hizmetlerin kullanımı için belli/özel bir yazılıma gereksinim duyuluyorsa bu durum belirtilmelidir.

- Simgeler ve metinler standart olmalı, aynı yere yapılan bağlantılarda ayn! ifade ve simge tercih edilmelidir.

- Görüntü ve metin bir bütünlük ve denge içinde tasarlanmalıdır. Grafikler ve fotoğraflar sayfayı çekici yapmakla birlikte, çok büyük boyutlu resimlerin erişimi yavaşlatacağı düşünülerek dikkatli kullanılmalıdır.

- Yabancı kullanıcılar için ya eşdeğer İngilizce Web sayfaları ya da kısa Ingilizce açıklamalar hazırlanmalıdır. 
- Farklı bilgisayarların ve/veya tarayıcıların değişik görüntü verebileceği göz önüne alınarak, hazırlanan sayfalar yaygın kullanılan tarayıcı programlarla test edilmelidir.

- Web sitesinin akılda kalıcı bir URL adresine sahip olması tercih edilmelidir. Uzun adresler ve dosya isimlerinden kaçınılmalıdır.

- Web sitesinin birçok kullanıcının hareket noktası olan arama motorlarında dizinlenmesi sağlanmalıdır.

Kütüphane Web sitelerinin içeriği ve kullanıcı beklentilerine yönelik yeni araştırmaların yapılması daha etkin sitelerin geliştirilmesini mümkün kılacaktır. Web tasarımı ile ilgili özgün çalışmaların yapılması da yararlı olacaktır.

\section{Kaynakça}

Agingu, B.O. (2000). Library web sites at historically black colleges and universities. College \& Research Libraries, 61(1): 30-37.

Akgül, M. (1999). Internet: Sunucu araçları ve yönetimi. Ankara: Bilkent Üniversitesi.

Balas, J.L. (1998). Using the web to market the library. Computers in Libraries, 18(9): 46-49.

(1999). The don'ts of web page design. Computers in Libraries, 19(8): 4648.

(2000). Doing it right: Web design for library types. Computers in Libraries, 20(1): 56-59.

Chisenga, J. (1998). A study of university libraries' home pages in Sub-Saharan Africa. Libri, 48(1): 49-57.

Clausen, H. (1999a). User-oriented evaluation of library and information centre Web sites. New Library World, 100(1146): 5-10.

. (1999b). Evaluation of library web sites: the Danish case. The Electronic Library, 17(2): 83-87.

Clyde, A. (1999). Ten things I hate about...web pages. Teacher Librarian, 27(2): 58-59.

Clyde, L.A. (2000). A strategic planning approach to web site management. The Electronic Library, 18(2): 97-108. 
Cohen, L.B. ve Still, J.M. (1999). A comparison of research university and two-year college library web sites: Content, functionality and form. College \& Research Libraries, 60(3): 275-289.

Cottrell, J. ve Eisenberg, M.B. (1997). Web design for information problem solving: Maximizing value for users. Computers in Libraries, 17(5): 52-57.

D'Angelo, J. ve Little, S.K. (1998). Successful web pages: What are they and do they exist? Information Technology and Libraries, 17(2): 71-81.

December, J. (1994). Challenges for web information providers. Computer-mediated Communication [Çevrimiçi], 1(6):8-14, Elektronik adres: http://www.ibiblio.org/cmc/mag/1994/oct/webip6.html [18 Kasım 2000].

Jurist, S. (1996). Top 10 rules for creating graphics for the web. College \& Research Libraries News, 57(7): 418-421.

King, D.L. (1998). Library home page design: A comparison of page layout for frontends to ARL library web sites. College \& Research Libraries, 59(5): 458-465.

Kredel, H., Meuer, H.W., Schumacher, R. ve Strohmaier, E. (2000). Internet and www: an introduction. [Çevrimiçi]. Elektronik adres: http://www.uni-mannheim.de/rum/dokus/intro.htm [10 Ekim 2000].

McClements, N. ve Becker, C. (1996). Writing web page standards. College \& Research Libraries News, 57(1): 16-17.

Nicotera, C.L. (1999). Information access by design: Electronic guidelines for librarians. Information Technology and Libraries, 18(2) 104-108.

Poulter, A., Tseng, G. ve Sargent, G. (1999). The library and information professional's guide to the world wide web. London: Library Association Publishing.

Quinn, B. (1999). Missing links: a survey of library systems department web pages. Library Hi Tech, 17(3): 304-315.

Rowley, J. (1998). The electronic library, London: Library Association Publishing.

Shemberg, M. (2000). Through the web: door to academic libraries. Reference Services Review, 28(2): 178-187.

Stover, M. (1997). Library Web sites: Mission and function in the networked organization. Computers in Libraries, 17(Nov/Dec): 55-57.

Tennant, R., Ober, J. ve Lipow, A.G. (1996). Internet el kitabı. (Çev. Yaşar Tonta ve diğerleri). Ankara: Türk Kütüphaneciler Derneği. 
TERENA. (1999). Internet kullanicısının ağ erişim rehberi. (Çev. Özgür Sezer). Ankara: TÜBITAK ULAKBIM.

White, C. ve Raman, N. (1999). The world wide web as a public relations medium: The use of research, planning and evaluation in web site development. Public Relations Review, 25(4): 405-419.

Yükseköğretim Kurulu. (2000). Üniversiteler. [Çevrimiçi]. Elektronik adres: http://www.yok.gov.tr/univbil/oku2.html [25 Eylül 2000]. 


\section{Ek 1. Üniversite Kütüphanelerinin Web Sitelerinin Adresleri}

\begin{tabular}{|c|c|}
\hline Üniversite & Kütüphane Web Adresi \\
\hline Adnan Menderes & http://www adu,edu.tr/kutuphane/ \\
\hline Afyon Kocatepe & http://www aku.edu.tr/kutuphane/kutuph.hIml \\
\hline Akdeniz & http://www akdeniz.edu.tr/internet/kutuphane/kutuphane.htm \\
\hline Anadolu & http://www.kdm.anadolu.edu.tr \\
\hline Ankara & http://bil-sis.ankara.edu.tr/ \\
\hline Balıkesir & http:/web.balikesir.edu.tr/kutuphane/htmi/index.htm| \\
\hline Boğaziçi & http://www library boun.edu.tt/ \\
\hline Cekal Bayar & http //www bayar.edu.tr/kutuphane/ \\
\hline Cumhuriyet & http://www cumhuriyet.edu.tr/birimler/idari/kutuphane/ \\
\hline Çukurova & http:/library.cu.edu.tr/ \\
\hline Dicte & http:/www.dicle.edu.tr/Kitap/ \\
\hline Dokuz Eylül & http:/Www,deu,edu,tr/admin/kutuphane/ \\
\hline Dumlupinar & http:/Kutup.dumlupinar.edu.tr \\
\hline Ege & http://www.ege.edu.tr/kutuphane/ \\
\hline Firat & http:/www.firat.edu.tr/kutuphane.htm \\
\hline Gazi & http://www lib.gazi.edu.tr \\
\hline Gaziosmanpaşa & http://www.gop.edu.tr/kutuphan.htm \\
\hline Gebze YTE & http://www.bilmuh.gyte.edu.t/pages/ htakci/gyteku/ \\
\hline Hacettepe & http://www.library.hacettepe.edu.tr/ \\
\hline İnönü & http://www.inonu.edu. Ir/? menu=library \\
\hline İstanbul Teknik & http://www.library.itu.edu.tr/indextur.html \\
\hline K.Maraş Sütçü İmam & http://www.ksu.edu.tr/Library/lndex 1.htm \\
\hline Karadeniz Teknik & http://www.ktu.edu.tr/library/nets/indexnets.htm \\
\hline Kırıkkale & http:/www.kku.edu.tr/ kutuphan/ \\
\hline Kocaeli & http://www.kou.edu.tr/kutuphane/Default.htm \\
\hline Marmara & http:/www.library.marun.edu.tr/ \\
\hline Mersin & http:/Www. mersin.edu.tr/kutuphane.html \\
\hline Ondokuz Mayıs & http:/www.omu.edu.tr/mkutup/MERK.htm \\
\hline Orta Doğu Teknik & http://www.lib.metu.edu.tr/ \\
\hline Pamukkale & http:/Www pamukkale edu.tr/kutuphane/kutuphane.htm! \\
\hline Sakarya & http://www.kutuphane.sakarya.edu.tp/ \\
\hline Selçuk & http://kutuphane.selcuk.edu.tr/ \\
\hline Süleyman Demirel & http://ibrary.sdu.edu.tr/ \\
\hline Trakya & http:/www.trakya.edu.tr/kutuphane/ana.htm \\
\hline Uludağ & http://www.uludag.edu.tr/turkish/ibrary/ibrary.htm \\
\hline Yıldız Teknik & http://ana.cc.yildiz.edu.tr/ library/kapak.html \\
\hline Yüzüncü Yil & http://kutuphane.yyu.edu.tr/ \\
\hline
\end{tabular}




\section{Ek 2. Üniversite Kütüphanelerinin Web Sitelerini Içerik Açısından Değerlendirme Ölçütleri}

\section{Web sitesi ile ilgili ölcüller}

1- Üniversite ana sayfalarından kütüphane sayfasına bağlantı var mı?

2- Kütüphane sayfasından üniversite sayłasına bağlantı var mı?

3- Son güncelleme tarihi var $m !$ ?

4- Web sayfası yazarının adı veya adresi var mı?

Temel kütüphane bilgileri içeren savfalarla ilgili ölçütler

5- Kütüphane hakkında bilgı var mı?

6- Kütüphane erişim bilgileri (kütüphane adresi, telefon numarası veya taks) var mı?

7- Çalışma saatleri hakkında birgi var mı?

8- Kütüphane personeli hakkında bilgi var mı?

9- Kütüphane kullanımı ve ödünç verme ile ilgifi bilgiler var mı?

Bilgi hizmetteri ile ilqili ölcuutler

10. Çevrimiçi kataloğu var mı?

11- Süreli yayın listesi var m?

12- Süreli yayın mevcutlar listesi var mı?

13- Yeni yayınlar veya duyurular veriliyor mu?

14- Internet'teki çevrimiçi veri tabanlarına veya elektronik dergilere bağlantı var mı?

Etkileșimli sayfalarla ilgili ölçütler

15- Kütüphanelerarası belge sağlama hizmetini destekliyor mu?

16- Site içinde arama yeteneği var mı?

17- Yardım veya sıkça sorulan sorular sayłası var mı?

18- Geribild’rim olanağı var mı?

Diğer: Uzaktaki bilgi kaynaklarına bağlantılarla ilgili ölcüt

19. Kendi üniversite sitesi dışındaki başka sitelere bağlantı var mı? 


\section{Ek 3. Üniversite Kütüphane Sitelerini içerik Açısından} Değerlendirme Tablosu

\begin{tabular}{|c|c|c|c|c|c|c|c|c|c|c|c|c|c|c|c|c|c|c|c|c|}
\hline \multirow[b]{2}{*}{ Adı } & \multicolumn{4}{|c|}{$\begin{array}{l}\text { Site/sayfalar } \\
\text { Olçüt No. }\end{array}$} & \multicolumn{5}{|c|}{$\begin{array}{l}\text { Kütüphane } \\
\text { Bilgilerri } \\
\text { Ölçït No. }\end{array}$} & \multicolumn{5}{|c|}{$\begin{array}{c}\text { Bilgi Hizmetieri } \\
\text { Ölçüt No. }\end{array}$} & \multicolumn{4}{|c|}{$\begin{array}{l}\text { Etkileşimli } \\
\text { Ölçüt No. }\end{array}$} & \multirow{2}{*}{$\begin{array}{l}\text { Diğer } \\
\text { Ölçüt } \\
\text { No. } \\
19 \\
8\end{array}$} & \multirow{2}{*}{$\begin{array}{c}\text { Toplam } \\
\text { Ö́çüt } \\
\text { Sayıs } \\
\end{array}$} \\
\hline & 12 & 3 & 4 & & 5 & 6 & 7 & 8 & 9 & 10 & 11 & 12 & 13 & 14 & 15 & 16 & 17 & 18 & & \\
\hline Boğaziçi & ++ & - & + & & + & + & + & + & + & + & + & + & + & + & + & + & + & + & + & $\overline{18}$ \\
\hline Hacettepe & ++ & + & & & + & + & + & + & + & + & + & + & + & + & + & - & - & + & + & 17 \\
\hline iTÜ & ++ & + & + & & + & + & + & + & + & + & + & + & + & + & + & - & - & + & + & 17 \\
\hline ODTÜ & +- & + & + & & + & + & + & + & + & + & + & + & + & + & + & - & + & + & + & 17 \\
\hline A. Menderes & ++ & + & + & & + & + & + & + & + & 0 & + & + & + & + & + & + & - & + & + & 16 \\
\hline K.Maraş S.i. & ++ & - & + & & + & + & + & + & + & + & + & + & + & + & + & - & - & + & + & 16 \\
\hline Sakarya & ++ & + & + & & + & + & + & + & + & + & + & - & + & + & + & - & . & + & + & 16 \\
\hline Çukurova & ++ & - & + & & + & $\cdot$ & + & + & + & + & + & + & + & + & + & - & $\cdot$ & + & + & 15 \\
\hline Ege & ++ & - & - & & + & + & + & + & + & + & + & + & + & + & + & - & 0 & + & + & 15 \\
\hline Gazi & + & - & + & & + & + & + & + & + & + & + & + & + & + & + & - & - & + & + & 15 \\
\hline Firat & ++ & - & + & & + & + & + & - & + & + & + & 0 & + & + & + & . & - & + & + & 14 \\
\hline 19 Mayıs & + & - & + & & + & - & + & + & + & + & + & + & + & + & + & - & - & + & + & 14 \\
\hline S. Demirel & +- & - & + & & + & - & + & + & + & + & + & + & + & + & + & - & - & + & + & 14 \\
\hline Kocaeli & ++ & - - & - - & & + & + & + & + & + & 0 & + & - & + & + & + & + & - & + & + & 13 \\
\hline Trakya & + & - & - & & + & + & + & + & + & + & + & - & + & + & + & - & - & + & + & 13 \\
\hline Cumhuriyet & +- & - & - & & + & + & + & + & + & - & + & - & + & + & + & - & $=$ & + & + & 12 \\
\hline 9 Eylül & ++ & - & - - & & + & + & 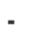 & + & + & + & + & - & + & + & - & - & - & + & + & 12 \\
\hline İnönü & ++ & - & + & & - & - & + & + & - & + & + & + & - & + & - & + & - & + & + & 12 \\
\hline KTÜ & $+t$ & - & + & & + & - & + & + & + & + & + & - & + & - & + & - & - & - & + & 12 \\
\hline 100. YII & + & - & - & & + & + & $\cdot$ & + & + & + & + & 0 & + & + & + & - & - & + & + & 12 \\
\hline Selçuk & ++ & + & $+=$ & & + & + & + & + & + & + & - & - & 0 & + & - & - & - & + & + & 12 \\
\hline Anadolu & +- & - & - & & + & + & + & + & - & + & + & + & + & + & - & - & - & + & - & 11 \\
\hline GYTE & $+=$ & - & + & & + & - & + & + & + & + & + & - & - & + & - & - & - & + & + & 11 \\
\hline Akdeniz & ++ & - & + & & + & - & . & + & - & 0 & - & - & + & + & + & - & - & + & + & 10 \\
\hline Marmara & ++ & - & - & & 0 & + & $=$ & 0 & 0 & + & + & \pm & + & + & 0 & - & - & + & + & 10 \\
\hline A. Kocatepe & ++ & - & - & & + & - & + & + & + & - & - & - & - & + & + & - & - & - & + & 9 \\
\hline Balıkesir & 0 - & - & - & & + & + & + & + & + & - & + & + & 0 & - & - & - & $=$ & + & - & 8 \\
\hline Dicle & + & - & - & & + & - & & + & $\cdot$ & - & + & - & + & + & + & - & - & - & + & 8 \\
\hline G.O.P. & ++ & - & - & & + & $\cdot$ & - & $\cdot$ & - & 0 & - & = & + & + & - & - & - & - & + & 6 \\
\hline Dumlupınar & $-\quad+$ & - & - & & + & - & . & + & + & - & - & - & - & - & . & - & - & + & 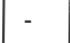 & 5 \\
\hline Ankara & $+\cdot$ & - & - & & - & - & - & - & - & + & + & - & - & - & - & - & - & + & - & 4 \\
\hline Celal Bayar & ++ & - & - & & - & - & & - & - & - & + & - & - & - & . & - & - & - & + & 4 \\
\hline Pamukkale & ++ & - - & - & & $=$ & - & - & - & $\cdot$ & - & $\cdot$ & - & - & + & - & - & - & - & + & 4 \\
\hline Yldiz Teknik & + & - & - & & - & - & & . & - & - & + & + & - & - & - & - & - & - & - & 3 \\
\hline Kirtkkale & $+\cdots$ & - & - & & + & - & 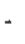 & $\cdot$ & - & - & - & - & - & - & - & - & $\cdot$ & - & n & 2 \\
\hline Mersin & ++ & - & - & & - & - & 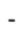 & - & - & - & - & - & - & - & - & - & - & - & - & 2 \\
\hline Ulưdağ & + & - & - & & . & - & 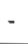 & - & - & - & - & - & - & + & - & - & - & - & - & 2 \\
\hline
\end{tabular}

Not: Öıçüt numaralarının karşıı̆ı için Ek 2'ye bakınız. 